Beck, H. P., Rorrer-Woody, S., \& Pierce, L. G. (1991). The relations of learning and grade orientations to academic performance. Teaching of Psychology, 18(1): 35-37. (Feb 1991) Published by Taylor \& Francis (ISSN: 1532-8023).

\title{
The Relations of Learning and Grade Orientations to Academic Performance
}

Hall P. Beck, Sherry Rorrer-Woody, and Linda G. Pierce

\begin{abstract}
This investigation assessed the roles of learning orientation (LO) and grade orientation (GO) in academic performance. Most important, we found that GO was negatively correlated with grade point average (GPA) and General Psychology test scores. Correlations of LO scores with the academic performance measures were not significant. The poor academic performance of students with high GO scores can be partially attributed to lower Scholastic Aptitude Tests (SAT) scores. Even after the effects of SA T were controlled, GO scores were negatively related to G PA and psychology test scores. These findings demonstrate the need for investigations to determine the effects of grading practices on students with high and low grade orientations.
\end{abstract}


Most investigations of college academic achievement have examined the relation between ability and academic performance. Relatively few studies have considered how differences in student motivation influence achievement. Milton, Pollio, and Eison's (1986) analysis of learning orientation (LO) and grade orientation (GO) provides an excellent framework from which to study two of the more prominent motivations of college students.

Learning-oriented students are excited by the opportunity to acquire new knowledge, and they find personal enrichment through academic experiences. Grade-oriented students base their actions on an instructor's evaluation procedures, and they work for grades. Separate LO and GO scores are obtained by administering the LOGO II Scale (Eison \& Pollio, 1989).

Learning orientation and GO have been related to SAT (Harris \& Harris, 1987; Johnson \& Beck, 1988) and American College Test (Rogers, Palmer, \& Bolen, 1988) scores. Correlations of LO and GO scores with academic ability tests suggest the possibility that analogous associations would be found between LOGO scores and course grades or classroom test results. To our knowledge, however, no studies have established significant correlations between LO or GO and class performance. Nonsignificant correlations have been reported between LOGO scores and high school GPA (Harris \& Harris, 1987), college GPA (Rogers et al., 1988), and test scores in a college introductory psychology class (Kauffmann, Chupp, Hershberger, Martin, \& Eastman, 1987).

Although previous studies have not found that LO or GO are related to class performance, the issue deserves further inquiry. In this investigation, we correlated LOGO II scores with two measures of academic performance: college GPAs and test scores in a General Psychology course. In addition to LO and GO, SAT was included as an independent variable to determine if the relations of LOGO II scores to GPA and psychology test scores are mediated by differences in academic ability.

\section{METHOD}

\section{Subjects}

Subjects were 110 undergraduates enrolled in two General Psychology sections taught by Hall P. Beck, the first author. Seventy-six percent of the students were freshmen, $19 \%$ sophomores, $3 \%$ juniors, and $2 \%$ seniors. 


\section{Procedure}

LOGO II consists of 16 LO and 16 GO items rated on a 5point Likert-type scale. The psychometric properties of LOGO II have been evaluated previously (Eison \& Pollio, 1989).

Students completed LOGO II during a regular class meeting early in the semester. Students were told that the data from the questionnaire would be used in several classroom demonstrations and that their responses would be confidential.

Four multiple-choice tests were administered during the semester. Approximately half of the questions were taken from the test bank (Bootzin, Bower, \& Zajonc, 1986) for the required textbook (Bootzin, Bower, Zajonc, \& Hall, 1986). The remaining questions were written by the instructor and based on lecture material. When the tests were returned, students received a letter grade and were told the percentage of questions correctly answered.

The objectives of the study were explained to the students near the end of the semester. All, except five students who were absent from class, granted permission to use their LO, GO, SAT, GPA, and psychology test scores for research purposes. The data from the five absent students were not included in the analysis. The SAT scores and GPAs (based on a 4-point scale) were furnished by the registrar.

\section{RESULTS}

Subjects' mean LO score was $47.10(S O=6.64)$, and their mean GO score was $43.82(S O=6.59)$. These values are comparable to those of other college samples (Eison \& Pollio, 1989). The SATs of our subjects averaged 916.64 $(S O=118.94)$, and their GPAs averaged 2.43 (SO = 0.72). The mean psychology test score for the sample was $73.82 \%$ (SO $=9.57$ ). The Spearman-Brown equation yielded split-half reliabilities ranging from. 56 to. 78 (median $=.73$ ) for the four psychology tests.

Learning orientation (Table 1) was negatively correlated with GO, indicating that students with high LO scores were less grade oriented than students with lower LO scores, $p<$ .05. Correlations of LO with SAT, GPA, and mean psychology test scores were not significant, all $p s>.05$. Grade orientation was negatively correlated with SAT, GPA, and psychology test scores, all $p s<.01$. As anticipated, SAT, 
GPA, and psychology test scores were positively correlated, all $p s<.01$.

Two commonality analyses (Kerlinger \& Pedhazur, 1973) further explored the correlations between GO scores and the academic performance measures. The first analysis used GO and SAT scores to predict GPA. The GO variable made a significant unique contribution to the accounted for variance, $\mathrm{F}(\mathrm{l}, 106)=3.97, P<.05$. The variance unique to SAT was also significant, $\mathrm{F}(1,106)=10.36, P<.01$, as was the accounted for variance common to GO and SAT, F( 1, $106)=4.72, p<.05$. In the second analysis, mean psychology test scores were the dependent measure and GO and SAT were the independent variables. As in the first analysis, the variances unique to GO and SAT were significant, $\mathrm{F}(\mathrm{l}, 106)=5.57, p<.05 ; \operatorname{andF}(\mathrm{l}, 106)=17.21, \mathrm{p}<.01$, respectively. The variance common to $\mathrm{GO}$ and SAT was also significant, $\mathrm{F}(\mathrm{l}, 106)=7.29, P<.05$.

Table 1. Correlations of LO, GO, SAT, GPA, and Psychology Test Scores

\begin{tabular}{lcccc}
\hline Scale & GO & SAT & GPA & PSY \\
\hline LO & $-.23^{*}$ & .10 & .16 & .09 \\
GO & - & $-.27^{* *}$ & $-.26^{* *}$ & $-.31^{* *}$ \\
SAT & & - & $.35^{* *}$ & $.42^{* *}$ \\
GPA & & & - & $.72^{* *}$ \\
\hline
\end{tabular}

Note. $\mathrm{LO}=$ learning oriented; $\mathrm{GO}=$ grade oriented; SAT $=$ Scholastic Aptitude Test; GPA = grade point average; PSY = General Psychology test scores.

${ }^{*} p<.05$, two-tailed. $" p<<.01$, two-tailed.

\section{DISCUSSION}

Commonality analyses revealed that the negative correlations of GO with GPA and psychology test scores were partially due to an element shared by GO and SAT. This result suggests that relatively low levels of academic ability contributed to the poor grades of highly grade-oriented students.

Johnson and Beck (1988) speculated that students with marginal academic skills are compelled to be highly grade oriented because they are under greater evaluative pressure, than their more academically talented peers. According I,) 
this explanation, students with low SAT scores believe that they must pursue grades or jeopardize their chances for academic survival. Students with higher SAT scores do not feel that they must be highly grade oriented in order to avoid failing college. Another interpretation of the inverse relationship of GO and SAT scores is that excessive interest in grades impedes the growth of academic skills.

Even after taking into account differences in SAT scores, GO was negatively related to CPA and psychology test scores. Prior research suggests that either ineffective studl habits (Eison \& Pollio, 1986) or high levels of debilitating test anxiety (Eison, Pollio, \& Milton, 19H6) could have contributed to the low grades earned by highly grade-oriented students. Also, informal discussions with students indicate that highly grade-oriented persons study different aspects of the course material than do less grade-oriented persons. Highly grade-oriented students concentrate only on the questions they believe will be asked on the test; less grade-oriented students study d broader spectrum uf course' material. If students are relatively ineffective predictors of the items professors select for test questions, then the restricted focus of highly grade-oriented students could lead to low test scores.

Although our correlational study does not demonstrate that the pursuit of grade;, causes substandard :ICadel1llc achievement, it is disconcerting that those students who are most motivated by grades are characterized by poor academic performance. We believe that this finding highlights the need for researchers to determine if grading pressures impact the performance of highly grade-oriented student. These investigations will increase our understanding of grade Orientation and may produce recommendations that improve instructional effectiveness. 


\section{REFERENCES}

Bootzin, R. R., Bower, G. H., \&Zajonc, R. B. (1986). Test item file to accompany Psychology today: An introduction (6th ed.). New York: Random House.

Bootzin, R. R., Bower, G. H., Zajone, R. H., \& Hall, E. (19H6) Psychology today: An introduction (6th ed.). New York: Random House.

Eison, J. A., \& Pollio, H. R. (1986). A multidimensional approach to the definition of college students' learning styles. Journal of College Student Personnel, 27, 434-443.

Eison, J. A., \& Pollio, H. R. (1989). LOGO II bibliographic and statistical update. Cape Girardeau, MO: Southeast Missouri State University, Center for Teaching and Learning.

Eison, J. A., Pollio, H. R., \& Milton. O. (1986). Educational and personal characteristics of four different type, of learning- and grade-oriented students. Contemporary Educational Psychology, II, 54-67.

Harris, C. M., \& Harris, J. S. (1987, March). Learning orientation and academic achievement. Paper presented at the annual meeting of the Southeastern Psychological Association, Atlanta.

Johnson, B. G., \& Beck, H. P. (1988). Strict and lenient grading scales: How do they affect the performance of college students with high and low SAT scores? Teaching of Psychology, 15, $127-$ 131.

Kauffmann, D. R., Chupp, B., Hershberger, K., Martin, L., \& Eastman, K. (1987). Learning vs. grade orientation: Academic achievement, self-reported orientations, and personality variables. Psychological Reports, 60, 145-146.

Kerlinger, F. N. \& Pedhazur, E. ]. (1973). Multiple regression in behavioral research. New York: Holt, Rinehart \& Winston.

Milton, O., Pollio, H. R., \& Eison, J. A. (1986). Making sense of college grades, San Francisco: Jossey-Bass.

Rogers, J., Palmer, W., \& Bolen, L. (1988, March). In pursuit of lifelong learning: A comparison of learning and grade orientation of freshmen and seniors. Paper presented at the annual meeting of the Southeastern Psychological Association, New Orleans. 